\title{
A IMPORTÂNCIA DO PROJETO POLÍTICO PEDAGÓGICO PARA A INSTITUIÇÃO DE ENSINO: ESCOLA MUNICIPAL EMÉRITO NESTOR LIMA
}

\author{
Afonso Ribeiro Damasceno Neto ${ }^{1}$ \\ Águida Dionízio Benevides de Paiva Figueira ${ }^{2}$ \\ Cristiano Araújo da Silva ${ }^{3}$ \\ Geilza de Lima Abdias da Silva ${ }^{4}$ \\ Jadna Tavares da Silveira ${ }^{5}$ \\ Josefa Poliana Clementino Ferreira ${ }^{6}$
}

RESUMO: O referido artigo científico trata da importância dada ao projeto político pedagógico em uma instituição de ensino de um bairro periférico no município de Parnamirim-RN, para tanto foi aplicado um questionário com 16 questões fechada para 25 professores dos 45 totais que existem na escola, além de conversas informais, nas quais pedimos permissão para anotar algumas respostas e enriquecer o trabalho de pesquisa, todos os resultados foram tabulados e os dados transformados em gráficos para ajudar na compreensão das respostas apuradas, então usamos como objetivos, verificar a existência do Projeto Político Pedagógico, analisar o processo de construção e aplicação prática do "PPP” na Escola Municipal Emérito Nestor Lima, no bairro Passagem de Areia em Parnamirim-RN. Diante disto procuramos entender o processo de divulgação, construção, aplicação e avaliação do "PPP" de uma escola municipal de ensino fundamental II, nosso resultados foram muito satisfatório, pois conseguimos perceber falhas na construção do

${ }^{\mathrm{I}}$ Graduado em Física licenciatura pela UFRN 2002/2005 Professor efetivo do estado RN e Município Parnamirim Mestrando em educação Assessoria e Consultoria Educacional (ESL) E-mail: afonsoribeirozoo6@gmail.com

${ }^{2}$ Graduada em Pedagogia Unifacex. 2005.I até 2009.I Pós-graduada em Psicopedagogia clínica e institucional

Universidade Potiguar - UNP Conclusão em 2016 - Mestranda em educação Assessoria e Consultoria Educacional (ESL) E-mail: aguida_dionizio@hotmail.com

${ }^{3}$ Graduado em pedagogia - UVA (Universidade Estadual Vale do Acaraú) - conclusão ano 20I8;

Bacharel em Direito - Universidade Potiguar (UNP), Conclusão 2020, Pós-Graduação: Docência na Educação Infantil e Anos Iniciais Universidade Cândido Mendes (UCAM), Conclusão 2020. - Mestranda em educação Assessoria e Consultoria Educacional (ESL) Email: cristiano29_araujo@hotmail.com

${ }^{4}$ Graduada em pedagogia -UVA (Universidade Estadual Vale do Acaraú) - conclusão ano 2009

Especialista em Educação Especial e Inclusiva - Faísa (Faculdade Santo Augusto) conclusão 2015,

Especialista em Educação de Jovens e Adultos no contexto da Diversidade- IFRN Campus Canguaretama/RN) Instituto Federal de Educação, Ciência e Tecnologia do Rio Grande do Norte, conclusão 2017,

Especialista em Psicopedagogia Clínica e Institucional - FACEN (Faculdade de Ciências Educacionais e Empresariais de Natal) conclusão 2020. - Mestranda em educação Assessoria e Consultoria Educacional (ESL) E-mail: geilzazo_lima@hotmail.com

${ }^{5}$ Graduada em bacharelado em Estatística - Universidade Federal do Rio Grande do Norte (UFRN) - 1997 200I

Graduação em licenciatura plena Matemática - Universidade Federal do Rio Grande do Norte (UFRN) - 2006/2010,

Especialização em Ensino da Matemática: pela Universidade Vale do Acara (UVA) -20ı/20II

Especialização em português e Matemática uma proposta transdisciplinar - Instituto Federal do Rio Grande do Norte (IFRN) 2013/2014. Mestranda em educação Assessoria e Consultoria Educacional (ESL)

Professora de Matemática efetiva e em exercício na sala de aula da rede municipal do Natal e de Lagoa de Pedras.Email: jad_silveira@hotmail.com

${ }^{6}$ Graduada em Matemática Licenciatura Plena pela Universidade Federal do Rio Grande do Norte - UFRN (2005.2)

Especialista em Práticas Educativas no Ensino Médio - Matemática pela Faculdade de Natal - FAL (2008.2)

Especialista em Educação Matemática: Teoria e Prática no Ensino Fundamental pelo Instituto de Educação Superior Presidente Kennedy (2009.2) Mestranda em educação Assessoria e Consultoria Educacional (ESL) Professora Efetiva da rede Estadual do Rio Grande do Norte e da rede municipal do Natal/RN. E-mail: poliana.ferreira.mat@gmail.com 
projeto político pedagógico, onde os próprios professores não conseguem perceber a participação da comunidade escola na construção do projeto, outro resultado interessante foi quanto a divulgação do PPP escolar, os professores e a gestão não divulgam o documento, não explicam aos pais, responsáveis e alunos o que é um projeto politico pedagógico, e qual a sua importância para a escola e a qualidade da educação, nas entrevistas os professores relataram que não foram apresentados ao projeto político pedagógico quando chegaram na escola e também falaram que não percebem a aplicação do projeto político pedagógico na instituição.

Palavras chaves: Projeto Político Pedagógico. PPP. Comunidade escolar. Gestão democrática.

ABSTRACT: The aforementioned scientific article deals with the importance given to the political pedagogical project in a teaching institution in a peripheral neighborhood in the municipality of Parnamirim-RN, for which a questionnaire with 16 closed questions was applied to 25 teachers of the 45 total that exist in the school, in addition to of informal conversations, in which we asked permission to write down some answers and enrich the research work, all the results were tabulated and the data transformed into graphs to help in the understanding of the calculated answers, so we used, as objectives, to verify the existence of the Pedagogical Political Project, to analyze the process of construction and practical application of the "PPP" in the Municipal School Emérito Nestor Lima, in the Passagem de Areia neighborhood in Parnamirim-RN. In view of this, we sought to understand the process of dissemination, construction, application and evaluation of the "PPP" of a municipal elementary school II, our results were very satisfactory, as we were able to perceive flaws in the construction of the pedagogical political project, where the teachers themselves cannot realizing the participation of the school community in the construction of the project, another interesting result was how much the dissemination of the school PPP, teachers and management do not disclose the document, do not explain to parents, guardians and students what a political pedagogical project is, and which its importance for the school and the quality of education, in the interviews the teachers reported that they were not introduced to the pedagogical political project when they arrived at the school and also said that they did not perceive the application of the pedagogical political project in the institution.

Keywords: Pedagogical Political Project. PPP. school community. Democratic management.

\section{O QUE É O PROJETO POLÍTICO PEDAGÓGICO?}

O projeto político pedagógico é um documento muito importante criado por toda comunidade escolar, onde ficam documentados os anseios de toda essa comunidade em relação ao futuro da escola, missão da escola, metas a serem alcançadas, objetivo geral e 
específicos, bem como as ações pedagógicas e metodologias para poder alcançar todos esses objetivos e garantir uma educação de qualidade para todos os educandos.

De acordo com Veiga (1995, p.12) o projeto político-pedagógico vai além de regras e métodos que vão ficar apenas no papel para apresentar as autoridades como u ma questão burocrática, para dizer que a escola possui o PPP, ele tem que ser vivido no chão da escola, colocado em prática cotidianamente ao dizer:

O projeto político-pedagógico vai além de um simples agrupamento de planos de ensino e de atividades diversas. O projeto não é algo que é construído e em seguida arquivado ou encaminhado às autoridades educacionais como prova do cumprimento de tarefas burocráticas. Ele é construído e vivenciado em todos os momentos por todos os envolvidos com o processo educativo da escola (VEIGA, 1995, p. 12).

Ainda seguindo o pensamento de Veiga e corroborando com Eyng (2002, p. 26) "Projeto porque faz uma projeção $\mathrm{da}$ intencionalidade educativa para futura operacionalização [...]" o PPP tem um poder de mudança nos rumos da escola, não é à toa que é chamado de Projeto por ser um esforço temporário que tem como finalidade um resultado único e possui recursos delimitados esse projeto pode ser social, pessoal, cultural, empresarial, educacional ou de pesquisa e por conter várias propostas concretas a serem executadas em um intervalo de tempo pré-determinado, neste caso atualizado a cada dois anos ou a cada mudança de gestão com a participação de toda a comunidade escolar.

Também é Político que significa "algo relacionado com grupos sociais que integram a Pólis", algo que tem a ver com a organização, direção e administração de nações ou Estados e neste caso especifico a escola, porque a escola é um espaço político, voltado à formação de cidadãos conhecedores de seus direitos e cumpridores de seus deveres, responsáveis, críticos e conscientes que atuem de forma individual e/ou coletiva na sociedade, ditando os caminhos para uma sociedade mais justa e melhor para vivermos.

E por último, não menos importante ele é pedagógico que se refere a ciência que se dedica ao processo de educação dos jovens, estudando os problemas que se relacionam com o seu desenvolvimento, pois há uma definição e organização das atividades e dos projetos educacionais a serem realizados no ambiente escolar para auxiliar no processo de ensino aprendizagem de nossos educandos tornando o cidadão que desejamos e que a sociedade precisa, quando o autor abaixo afirma: 
Projeto porque faz uma projeção da intencionalidade educativa para futura operacionalização [...], político porque define uma posição do grupo, supõe uma proposta coletiva, consciente, fundamentada e contextualizada para a formação do cidadão [...], pedagógica porque define a intencionalidade formativa, expressa uma proposta de intervenção formativa. (EYNG 2002. p. 26)

Concordamos com Eyng (2002, p. 26) que o projeto político pedagógico faz uma projeção do que a escola pretende alcançar, com a participação efetiva de toda a comunidade escolar traçando os caminhos a serem seguidos e trabalhando o fazer pedagógico para que as projeções sejam alcançadas. Dessa forma o PPP escolar nos tira da zona de conforto e nos faz ir mais além, buscar novo caminhos e novos objetivos, rompendo com o presente e gerando novas perspectivas para um futuro prospero.

Para Gadotti (1994) o projeto é uma quebra de paradigmas, é uma promessa de dias melhores para a escola, ao afirmar:

Todo projeto supõe rupturas com o presente e promessas para o futuro. Projetar significa tentar quebrar um estado confortável para arriscar-se, atravessar um período de instabilidade e buscar uma nova estabilidade em função da promessa que cada projeto contém de estado melhor do que o presente. Um projeto educativo pode ser tomado como promessa frente a determinadas rupturas. As promessas tornam visíveis os campos de ação possível, comprometendo seus atores e autores (GADOTTI, 1994, p. 579).

Unindo esses três conceitos o Projeto Político Pedagógico ou simplesmente usando a sigla "PPP" como é chamado pela comunidade escolar é uma força que guia a escola para um futuro melhor, concordamos que o PPP indica a direção a ser seguida por todos da comunidade escolar, por isso ele deve ser completo e não pode deixar dúvidas sobre os caminhos e também deve ser flexível para poder se adaptar às necessidades de aprendizagem dos alunos, por isso é necessário ter em mente na hora da elaboração alguns tópicos tias como: missão, clientela, dados sobre aprendizagem, principalmente boa comunicação e relação com a família, boa gerencia dos recursos, diretrizes pedagógicas e o plano de ação. O PPP é um planejamento da escola para proporcionar um futuro melhor na relação ensino-aprendizagem na vida dos educandos.

De acordo com Silva (2003); Estevam (2014), o PPP é a bussola orientadora dos caminhos a serem seguidos pela instituição escolar, conforme a afirmam abaixo:

[...] o projeto político-pedagógico da escola pública, eixo ordenador e integrador do pensar e do fazer do trabalho educativo. Se concebido adequadamente, revela 
quem é a comunidade escolar, quais são seus desafios com relação à boa formação à conquista da autonomia e da gestão democrática, capaz está de organizar, executar e avaliar o trabalho educativo de todos os sujeitos da escola... Eis o nosso desafio, recolocar o projeto político pedagógico no centro de nossas discussões e práticas, concebendo-o como instrumento singular para a construção da gestão democrática (SILVA, 2003, p. 298 apud ESTEVAM, 2014).

Corroborando com a citação dos autores, o Projeto Político Pedagógico é um documento capaz de organizar, avaliar e reorganizar o fazer pedagógico na escola, integrando metas e objetivos, conteúdos e metodologias, condições e ambiente escolar, os sujeitos com a qualidade, habilidades. Ele deve ser o centro das discussões e das práticas realizadas nas escolas e consiste de um instrumento muitíssimo importante de construção de uma gestão verdadeiramente democrática que escuta a sua comunidade escola e a conhece, entendendo as suas necessidades e buscando maneiras de atender e realizar os objetivos almejados. Como afirmam aos autores a seguir:

O Planejamento de Ações Educativas, articulando as metas aos objetivos, os fundamentos, os conteúdos e as estratégias metodológicas, considerando os contextos comunitário e escolar, as condições e o ambiente educacional, os sujeitos envolvidos, a qualidade, a habilidade e a experiência dos educadores (as) e o processo de avaliação e acompanhamento (SILVA; ZENAIDE, s/d).

A citação acima quando falam que o planejamento das ações educativas em uma instituição de ensino é de extrema importância para o desenvolvimento dos educandos, possibilitando o desenvolvimento de suas habilidades e competências para que possam exercer os seus direitos em sociedade e poder cumprir os seus deveres como cidadãos ativos e críticos na sociedade. Isso ressalta a importância de um PPP elaborado em parceria com toda a comunidade escolar para o bom desenvolvimento da relação ensino-aprendizagem.

Como afirma Padilha (2007, p. 44): "É preciso entender o projeto políticopedagógico como um situar-se num horizonte de possibilidades na caminhada, no cotidiano, imprimindo uma direção...”, ou seja, o projeto político da escola possui uma infinidade de possibilidades de caminhos a serem seguidos pela instituição para a realização dos desejos e sonhos. Somente desta maneira a comunidade escola poderá ver a verdadeira importância do PPP na escola e sua aplicação será mais efetiva por toda a comunidade escola de acordo com Veiga, (2006, p. 13) afirma: "o projeto político pedagógico busca um rumo, uma direção", a ser seguido por todos que fazem parte da comunidade escolar para que possam atingir os objetivos e metas traçados no projeto 
político pedagógico e somente após entender o projeto político pedagógico da escola ficaria mais fácil visualizar esse rumo e a linha de chegada, que seria a certeza do dever cumprido.

\section{IMPORTÂNCIA DO PROJETO POLÍTICO PEDAGÓGICO}

O projeto político pedagógico é muito importante para instituição escola por reunir todas as informações sobre a instituição escola e fazer uma projeção das metas e sonhos que a comunidade deseja alcançar em um futuro próximo ou não tão próximo assim.

E segundo Vasconcelos (2006, p. 17): “o projeto político-pedagógico é o plano global da instituição (...) trata-se de um importante caminho para a construção da identidade da instituição”. Diante disso, o Projeto Político Pedagógico é importante para a identidade da escola e ele informa o norte para escola, indicando os caminhos para uma educação de qualidade funcionando como um planejamento das ações a serem seguidas para que a escola escreva uma história de sucesso e prosperidade.

Ainda seguindo a visão de Vasconcelos (2006, p. 2I), quando afirma: "fortalecer o grupo para enfrentar conflitos, contradições e pressões, avançando na autonomia (caminhar com as próprias pernas) e na criatividade (descobrir o próprio caminho)”. Desta forma, observamos a necessidade de toda a comunidade está unida para transpor as barreira e adversidades que surgirem no caminho da instituição, tornando-a sólida e fortificada, isso será possível com a participação de toda comunidade escolar na construção do Projeto Político Pedagógico que é um documento que deve ter a participação de toda comunidade escolar em sua construção para que todos os olhares sobre a escola sejam contemplados, neste documento deverão constar os objetivos a serem alcançados, as metas a serem superadas, porque não dizer os sonhos a serem realizados, conforme verifica-se a seguir:

(...)se a participação efetiva das camadas trabalhadoras nos destinos da educação escolar for uma utopia no sentido apenas de um sonho irrealizável, e não no sentido que demos à palavra no início, então de nada adianta continuarmos falando de escola como algo que possa contribuir para a transformação social e, definitivamente, devemos deixar cair as máscaras e as ilusões com relação à escola que aí está e partir para outras soluções, ou então cruzar os braços e esperar passivamente que os grupos dominantes, por meio de suas "reformas e acomodações" de interesses continuem nos fazendo engolir as soluções paliativas que os mantêm perenemente no poder (PARO, 2002, p. 14). 
Diante a citação do autor, a participação da comunidade escolar não pode ser apena uma utopia, algo irrealizável, essa participação deve sim ser real e ativa, ou então, como podemos falar da escola como um instrumento de transformação social se o conjunto de aspirações e os métodos para realizá-los, que dará origem ao Projeto Político Pedagógico da escola que deve ser construído em união com toda a comunidade escolar, gestão, professores, pais e responsáveis e não menos importante os educandos que são a alma da escola, não fizeram parte da construção do documento.

Para entender melhor a importância do Projeto Politico Pedagógico no chão da escolar, aplicamos um questionário com 16 questões diretas de forma remota com os professores da Escola Municipal Emérito Nestor Lima, uma escola periférica localizada no bairro Passagem de Areia, município de Parnamirim-RN. A referida escola possui um total de 45 professores em distribuídos em três turno com um total de 22 turmas, onde 25 professores aceitaram fazer parte da pesquisa respondendo ao questionário e conversando informalmente sobre a instituição escolar.

Uma das repostas que nos chamou a atenção está no quesito I6 onde foi perguntado aos professores: "Qual o nível de importância na sua opinião do projeto político pedagógico para o desenvolvimento do educando de sua escola?”

As respostas foram tabeladas e possibilitaram a construção do gráfico a seguir que apresenta os resultados das respostas dos professores.

\section{Gráfico 16}

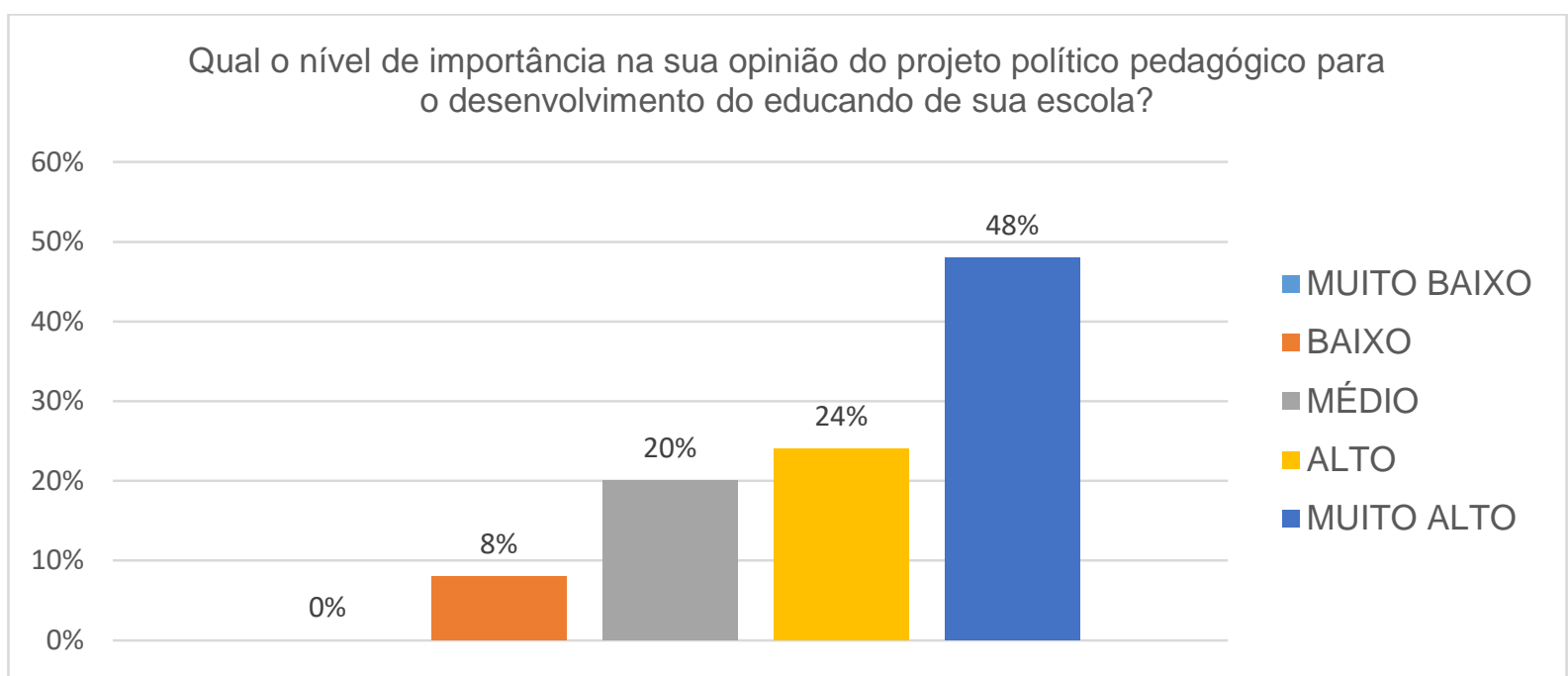

Fonte: Elaboração própria 
Analisando as respostas obtidas com os questionários, percebemos que $48 \%$ dos professores entendem que o PPP tem um nível de importância muito alto e mais $24 \%$ entendem que esse nível é alto, ou seja, mais da metade dos professores entrevistados reconhecem a importância do projeto político pedagógico.

Então acreditamos que esses professores fazem o projeto politico pedagógico acontecer na escola, realmente tirando-o do papel e vivenciando-o dentro da sala de aula.

\section{CONSTRUÇÃO DO PROJETO POLÍTICO PEDAGÓGICO}

A construção do Projeto Político Pedagógico sólido e eficaz é função/obrigação de toda a comunidade escolar, mas essa realidade está longe de ocorrer nas escolas públicas por vários fatores, um deles é a dificuldade em assumir a responsabilidade sobre a escola, a falta de empenho dos pais e responsáveis em assumir verdadeiramente a responsabilidade escolar do educando sobre a sua responsabilidade, outro fator é a falta de motivação e envolvimento ativo da própria gestão escolar.

Contudo o PPP deve ser construído com a participação de todos da comunidade escolar, garantindo o direito de voz e participação de todos, para que o documento represente verdadeiramente a alma da instituição escolar e atenda aos anseios e desejos de todos que compõem a comunidade escolar. Assim como afirma Vasconcellos (2006, p.27):

\footnotetext{
A elaboração participativa do projeto político-pedagógico é uma oportunidade ímpar de a comunidade definir em conjunto a Escola que deseja construir, avaliar a distância que se encontra do horizonte almejado e definir os passos a serem dados para diminuir esta distância (VASCONCELLOS, 2006, p. 27).
}

Segundo o autor supracitado deve haver uma participação ativa da comunidade escolar e que essa participação é uma oportunidade muito importante para que a comunidade escolar possa expressar todas as suas angústias e sonhos em relação ao futuro da relação ensino-aprendizagem na instituição escolar e quais objetivos devem ser traçados para sanar essas angústias e realizar os sonhos desejados.

Diante disto no quesito 12 foi perguntado aos professores: "Você percebeu a participação efetiva da comunidade escolar na construção do projeto político pedagógico?”

As respostas foram tabeladas e possibilitaram a construção do gráfico a seguir que apresenta os resultados das respostas dos professores. 


\section{Gráfico 12}

Você percebeu a participação efetiva da comunidade escolar na construção do Projeto Político Pedagógico?

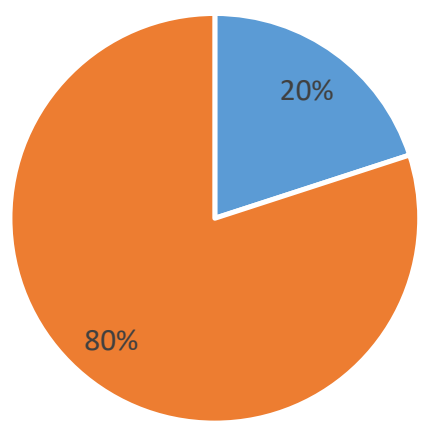

Fonte: Elaboração própria

E por incrível que pareça as respostas dos professore entrevistados surpreenderam, onde $80 \%$ dos professores entrevistados responderam que não percebem a participação da comunidade escolar na construção do PPP de sua escola. Isso vai na contramão do que os grandes autores da educação recomendam, que é a participação de toda a comunidade escolar.

Então ouvindo os professores informalmente para saber sobre as dificuldades na construção do projeto político pedagógico anotamos algumas justificativas para a não participação dos pais e responsáveis dos alunos.

Um dos professores nos relatou em conversa informal que:

[...] itas vezes não há o interesse dos pais e/ou responsáveis de participarem ativamente da vida escolar do seu filho e por isso não comparecem a reunião de pais, assembleias e/ou reuniões de avaliação e construção do projeto político pedagógico" (Entrevistado I)

[...] muitos pais e responsáveis trabalham o dia todo e por isso não podem vir a reuniões pedagógicas, as vezes só aparecem na instituição para pegar uma declaração do Bolsa Família ou renovar a matrícula para o ano seguinte" (entrevistado 2)

Por esse e outros motivos a participação da comunidade escolar não é percebida pelo corpo docente na construção do projeto político pedagógico, com isso, fica muito mais difícil identificar as reais necessidades da comunidade escola e construir verdadeiramente um PPP que tenha a cara da escola e mostre a sua identidade. Outro possível motivo é que 
pais e alunos não sabem o que é o projeto politico pedagógico, por isso criam essas barreiras a participarem da construção do PPP escolar, como eu vou participar da elaboração de um documento que eu não sei o que é e para que serve.

Neste caso a falta de participação da comunidade escolar vai de encontro com Veiga (200o, p. II) quando diz que o "Projeto Político-Pedagógico: uma construção coletiva", nesta situação observamos que a construção do projeto político pedagógico apresenta grandes dificuldades para gestão e a comunidade escolar, muitos pais e responsáveis não querem participar, não sabem o que é ou não foram convidados a participar da construção do PPP da sua escola, as vezes por falta de comunicação entre a escola e a comunidade escolar, outras vezes por falta de interesse dos pais em participar, ou por não saber do que se trata mesmo, e algumas vezes por falta de interesse dos gestores em convocar a comunidade para debater sobre os objetivos da escola, por isso em muitas escolas não existe o documento ou não é amplamente divulgado entre a comunidade escola e a própria comunidade escolar por não entender o que é um Projeto Político Pedagógico não o procura ou não tem o interesse em participar de sua construção, e, é muito importante que haja a participação de toda a comunidade escolar nos processos de construção, aplicação, avaliação, reflexão e reconstrução, já que o documento deve está em constante construção ao longo do processo de ensino aprendizagem.

De acordo com Gadotti (200o, p. 17) afirma: “(...) construir o projeto pedagógico de uma escola é mantê-la em constante estado de reflexão e elaboração numa esclarecida recorrência às questões relevantes de interesse comum e, historicamente, requeridos". Sendo assim, o Projeto Político Pedagógico é dinâmico, não para, sempre em ação no cotidiano da escola, refletir sobre essas ações é de suma importância para o sucesso da construção e aplicação do PPP, analisando o que deu certo e o que não deu, usando a tríade construção, reflexão, reconstrução, já que ele está sempre em construção.

Ferreira (2006, p. II2) informa: "quando fala que formarão as personalidades dos alunos e se fortalecerá cada um dos membros da escola". Portanto, um projeto político pedagógico bem construído com a participação de todos alcançará êxito na formação de cidadãos com uma personalidade crítica, consciente capaz de atuar em sociedade e os 
membros da comunidade escolar estarão mais fortes sabendo que seus objetivos foram alcançados e obtiveram resultados positivos na formação destes cidadãos ao dizer:

[...] se formarão as personalidades dos alunos e se fortalecerá cada um dos membros da escola que, conscientes dos objetivos a serem trabalhados, seu significado e os valores que os sustentam, reavaliarão, na sua própria prática, as suas vidas e as suas prioridades. Reside aí, neste processo de gestão da educação, o grande valor da construção coletiva e humana do projeto formador (FERREIRA, 2006, p. 112).

É notório que o mundo em vivemos hoje, onde as mudanças econômicas, sociais, e culturais são constantes, ocorrendo com uma rapidez imensurável, o que exige cada vez mais da escola novas formas de organização. É função da escola, como instituição educativa, criar de mecanismos e ferramentas que verdadeiramente levem à superação da ausência de valores da contemporaneidade. Concordamos com vários autores que apenas com um Projeto Político Pedagógico revolucionário e libertador poderá dar conta dessa função árdua.

De acordo com Moraes (2006) afirma: "o projeto deve ser pensado coletivamente com toda a comunidade escolar, articulado aos desejos da comunidade escolar, e deve auxiliar a instituição educacional a percorrer o caminho do diálogo, cuja divergência é entendida como oportunidade de renovação e não para destruição.”. Desta forma toda a comunidade escolar deve ser convocada a participar dos debates em relação aos objetivos da escola e dos sonhos a serem alcançados pela escola. Esse projeto político pedagógico é extremamente possível, porém não é uma tarefa tão fácil, precisa do empenho e engajamento de todos que fazem parte da comunidade escolar.

Neste sentido, segundo Ferreira (2006) informa a seguir:

O PPP: [...] deve ser pensado, estudado, refletido, debatido e construído coletivamente com o que existe, no mundo, de mais atual, mais avançado e de melhor qualidade para formar seres humanos fortes intelectualmente, ajustados emocionalmente, capazes tecnicamente e ricos de caráter (FERREIRA, 2006, p 17).

Concordamos com Ferreira (2006, p. 17) no que diz respeito ao PPP ser construído, pensado, estudado, refletido coletivamente, somente assim ele poderá ter verdadeiramente a identidade da escola em seus textos, com a participação de todos fica evidente que todos têm responsabilidades sobre o futuro da escola. 
Para Libâneo (2004) a participação de todos deixa explicita a responsabilidade de cada um sobre o destino da escola, responsabilidade que muitas vezes não quer ser assumida pelos membros da comunidade escolar, concordamos que cuidar da escola é uma responsabilidade grande e de toda a comunidade escolar, se não assumirmos essa responsabilidade a escola fica estagnada e fica em decadência até atingir o fundo do poço. Somente através da cooperação de todos, do diálogo com a comunidade que se pode entender essa responsabilidade e todos passarem a agir e direcionar suas atitudes em prol da instituição escolar quando diz:

No entanto, a ideia de participação, entendida como uma "modalidade de gestão
que, por meio da distribuição de responsabilidades, da cooperação, do diálogo, do
compartilhamento de atitudes e modos de agir... (LIBANEO, 2004, p. Io3).

Concordamos com Libâneo (2004, p. I03) que com a participação de toda a comunidade escolar, fortalece a gestão democrática e distribui a responsabilidade para todos de cuidar da escola e cooperar com o crescimento e desenvolvimento dos educandos. Unindo os professores e alunos, gestão e comunidade em um pensar coletivo.

Como afirma Santiago (2009), a gestão democrática tendo como instrumento o PPP:

[...] é um convite ao pensar - pensar coletivo. É prática docente-discente como ponto de partida e como ponto de chegada. É uma atitude frente a vida, à sociedade e à escola que devem serem colocadas como importante no processo de construção do PPP, como trabalho coletivo, de investigação e de intervenção pedagógica (SANTIAGO, 2009, p. I0I).

De acordo com a citação do autor, o PPP é uma oportunidade de pensarmos sobre a prática docente-discente como início de tudo e termos a capacidade de enxergamos o ponto de chegada, também a sociedade e a escola são as partes mais importantes na construção do Projeto Político Pedagógico. Em nenhum momento da construção do PPP da instituição escolar podemos esquecer necessidade da participação de todos da comunidade escola, deste modo o projeto político pedagógico dar-se-á de maneira fluida e espontânea e expressará os anseios e sonhos de toda uma comunidade a ser alcançada em um futuro não tão distante. Aplicação do PPP na escola

Notamos que uma parte importante quando tratamos de Projeto Político Pedagógico é garantir a sua aplicação na escola, o documento traz todos os anseios da 
comunidade escolar e não pode ser esquecido em uma gaveta, ou usado apenas para efeitos burocráticos, mostrar as autoridades e a secretaria de educação do município, nele está o futuro próximo da qualidade da educação na instituição escolar, a aplicação cotidiana e incansável do PPP irá transformar a realidade da escola e garantir que essa instituição realmente seja um espaço de aprendizagem e desenvolvimento, para isso é muito importante a participação de todos não só na construção do documento, mas também de maneira a garantir a sua aplicação para que os objetivos, metas e sonhos sejam alcançados, somente com o engajamento de todos isso será possível.

Diante disto no quesito 8 foi perguntado aos professores: "Quando chegou na atual escola que você trabalha, você foi apresentado ao projeto político pedagógico da escola?"

As respostas foram tabeladas e possibilitaram a construção do gráfico a seguir que apresenta os resultados das respostas dos professores.

\section{Gráfico 8}

Quando chegou na atual escola que você trabalha, alguém lhe apresentou o projeto político pedagógico da escola?

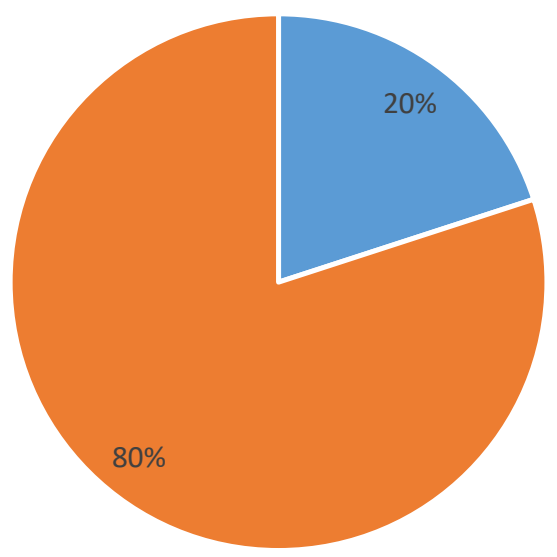

- SIM

- NAO

Fonte: Elaboração própria

Notamos que $80 \%$ dos professores entrevistado não foram apresentados ao projeto político pedagógico da escola, como é possível você chegar em uma empresa seja ela privada ou pública e não ser apresentado as regras, aos objetivos e as metas da instituição, 
acreditamos que isso tornará o trabalho do professor muito mais complicado e também cada docente irá trabalhar um objetivo diferente que não está em consonância com os objetivos da escola, bem como a comunidade escolar que sem conhecer o projeto político pedagógico não saberá o que cobrar da instituição em relação a qualidade da educação de seus filhos.

Em uma de nossas conversas informais um professor relatou que:

[...]chegando à escola no meu primeiro dia de aula como professor concursado, com o ano letivo em andamento, me apresentei a gestão escolar e a gestão me apresentou a coordenação e ao corpo docente e imediatamente me encaminhou para sala de aula, para eu ministrar minhas aulas, não fui informado sobre o PPP, sobre as normas da instituição, sobre o regimento ou outra coisa qualquer, apenas vá dá aula..." (Entrevistado I)

[...]quando cheguei na escola no início do ano, estávamos em semana pedagógica, falamos sobre vários temas, tais como: inclusão, bullying, calendário escolar, eventos da escola, planejamento, avaliação, porém não fui apresentado ao PPP escolar e esse nem sequer foi mencionado..." (Entrevistado 2)

Vejamos a falta de importância dada ao projeto político pedagógico, ele não é a peça principal da escola, não é tido como mais importante, assim a escola fica a deriva sem ter um rumo para o futuro e perde muito com a qualidade da educação.

Veiga e Resende (1998, p. 12) “A escola deve ser um espaço onde todos participem do planejamento e execução de todas as suas ações, onde o conjunto de valores, normas e relações obedecem a uma dinâmica singular e viva", observa-se que o projeto político pedagógico tem que ser vivido dentro da escola, por todos da comunidade escolar, como PPP é um documento construído por todos da comunidade escolar ou pelo menos deveria ser assim, então todos tem um pouco de responsabilidade em fazer com que ele seja aplicado no cotidiano da escola, ou seja, os próprios membros da comunidade devem agir como fiscalizadores da aplicação do Projeto Político Pedagógico, e, não pode-se deixar o documento ficar obsoleto, esquecido em uma gaveta apenas para cumprir a função burocrática, é nele onde estão programado os objetivos, metas, sonhos e as ações que irão guiar, dá rumo a escola para um futuro promissor, e deve ser constantemente analisado e reavaliado para que sempre atenda as mudanças da sociedade e da comunidade escolar.

Diante disto no quesito is foi perguntado aos professores: "Em algum momento em sua sala de aula, você ou alguém da equipe gestora entrou em sala para falar aos alunos sobre o projeto político pedagógico?” 
As respostas foram tabeladas e possibilitaram a construção do gráfico a seguir que apresenta os resultados das respostas dos professores.

\section{Gráfico 15 .}

Em algum momento em sua sala de aula, você ou alguém da equipe gestora entrou para fala aos alunos sobre o projeto político pedagógico?

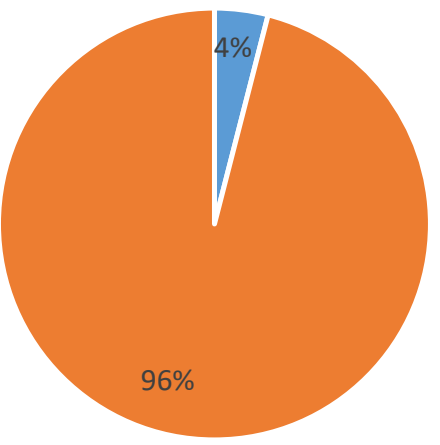

Fonte: Elaboração própria

Percebemos que $96 \%$ dos professores entrevistados afirmaram que não falam sobre

o PPP em sala de aula para os alunos e que a gestão também não entra em sala de aula para conversar sobre o projeto político pedagógico da escola, por isso não é surpresa que a comunidade não participe da construção do PPP escolar, como eles não sabem o que é o documento, não dão a devida importância para ele.

Em uma de nossas conversas informais um professor relatou que:

[...] já participei de várias reuniões de pais e mestres, e nunca foi falado sobre o projeto político pedagógico para os pais e responsáveis, nunca foi explicado o que é o PPP, qual a sua importância para a escola, apenas tratamos de notas, comportamento e eventos da escola..." (Entrevistado I)

[...]nas reuniões de pais e mestres que participei nunca ouvi falar sobre o projeto político pedagógico, parece mentira, mas realmente não falamos sobre o documento para os pais, por isso eles não se interessam em participar da construção, as vezes não é falado nem na semana pedagógica para os professores, (risadas)...” (Entrevistado 2$)$

Notamos a falta de comunicação entre gestão e comunidade escolar a respeito do PPP da instituição, existe uma falta de divulgação do documento, torna-lo acessível a toda comunidade, realizar treinamentos com a comunidade, coloca-lo em pauta em todas as reuniões para que a comunidade escolar passe a se familiarizar com o documento e passe a ter interesse em "ficar por dentro", ou seja, ajudar na sua construção e avaliação. 


\section{CONSIDERAÇÕES}

Neste artigo tentamos compreender como ocorre o processor de construção e aplicação do projeto politico em uma escola publica municipal no estado do Rio grande do Norte, trabalhamos com a aplicação de um questionário de pesquisa com i6 questões fechadas de múltipla escola e 25 professore que lecionam em três turnos distribuído em ensino fundamental 2 e educação de jovens e adultos (EJA), no entanto notamos uma dificuldade imensa da instituição escolar em reunir a comunidade escolar, para a construção do projeto político pedagógico da instituição, outra dificuldade percebida no questionário e nas entrevistas é que não há aplicação diária do projeto político pedagógico na instituição e que professores não são apresentados ao PPP ao chegarem na escola para lecionar pela primeira vez. Neste caso indicamos a gestão da escola um trabalho massivo de divulgação do documento, capacitações e treinamento para que toda a comunidade entenda o que é o PPP e qual a sua importância para o futuro a instituição escolar e a qualidade da educação. Acreditamos que somente desta maneira a instituição escolar poderá superar suas dificuldades na divulgação, construção e aplicação do projeto político pedagógico escolar com eficácia e destreza.

\section{REFERENCIAS}

EYNG, A. Projeto pedagógico: construção coletiva da identidade da escola, um desafio permanente. Revista Educação em Movimento, Curitiba. V. I - n.I p. 25-32. jan/abril 2002.

FAGUNDES, M. C. V. A implementação do Projeto Político-Pedagógico na escola Fundamental.

FERREIRA, Naura S.C Gestão democrática da educação: atuais tendências, novos desafios. $5^{\text {a }}$ ed. São Paulo: Cortez, 2006.

GADOTTI, Moacir. "Pressupostos do projeto pedagógico". In: MEC, Anais da Conferência Nacional de Educação para Todos. Brasília, 28/8 a 2/9/94.

LIBÂNEO, J. C. Organização e gestão da escola: teoria e prática. $5^{\underline{a}}$ ed. Goiânia: MF Livros, 2008.

PARO, V. H. Gestão da escola pública: a participação da comunidade. Revista Brasileira de Estudos Pedagógicos. Brasília, mai./ago. 1992. 
VASCONCELlOS, Celso Dos S. Coordenação do Trabalho Pedagógico. São Paulo: Libertad, $5^{\text {a }}$ ed. 2004 .

VEIGA, Ilma Passos Alencastro (org.). Projeto político-pedagógico da escola: uma construção possível. 22. ed. Campinas, SP: Papirus, 2006.

VEIGA, I. P. A. (org.). Quem sabe faz a hora de construir o projeto político-pedagógico. $2^{\underline{a}}$ Ed. Campinas/SP: Papirus, 2010. 